\title{
Bio-algae: a study of an interactive facade for commercial buildings in populated cities
}

Walaa Hussein Hussein Hanafi

Correspondence: walaahussien@
yahoo.com
Architectural Engineering
Department, Pyramids Higher
Institute for Engineering and
Technology, Giza, Egypt

Springer Open

\begin{abstract}
Climate change, global energy demand, and greenhouse emissions from energy (formerly $\mathrm{CO}_{2}$ emissions from fuel combustion) have emerged as the most serious threats to humans, particularly in densely populated cities. As a result, there are calls to reconnect with nature and draw inspiration from its mechanisms as well as to use clean renewable energy resources. Thus, this paper presents a biomimicry approach-a strategy for achieving ecological balance - to biofuel using algae in a building facade, and considers a case study building in Giza city as an example of a populated city in Egypt for retrofitting its skin with a nature-inspired solution. Using mathematical calculation, energy load analysis, and interviews with interested specialists, architects, and building occupants about this technology, then compared the performance of the case study commercial building facade with the proposed algae facade for energy generate. The results indicate that electrical energy consumption can be reduced by 45 to 50\%, and carbon emissions could be reduced. In addition, other benefits for the building environment and societal acceptance were revealed. The study concluded that using algae as an element of the building skin in densely populated cities as a biomimicry architecture strategy contributes to an innovative environmental approach.
\end{abstract}

Keywords: Nature, Algae, Populated cities, Inspirational facade, Biomimetic building envelope

\section{Introduction}

Global warming occurs as a result of the atmosphere trapping heat from the Earth and preventing it from being emitted into space. Between 1970 and 2004, industries expanded significantly, resulting in up to $70 \%$ increase in greenhouse gas emissions. $\mathrm{CO}_{2}$ is the most prevalent of these gases, having increased by $80 \%$ during this period [1-3].

Greater Cairo, Egypt, is one of the most populated cities in the world. As a result of urbanization and traffic congestion, it consumes a large amount of energy, and it is ranked one of the top ten cities in the world in terms of ambient air pollution, according to a World Health Organization report [4]. The city's topography, high-rise buildings,

(c) The Author(s). 2021 Open Access This article is licensed under a Creative Commons Attribution 4.0 International License, which permits use, sharing, adaptation, distribution and reproduction in any medium or format, as long as you give appropriate credit to the original author(s) and the source, provide a link to the Creative Commons licence, and indicate if changes were made. The images or other third party material in this article are included in the article's Creative Commons licence, unless indicated otherwise in a credit line to the material. If material is not included in the article's Creative Commons licence and your intended use is not permitted by statutory regulation or exceeds the permitted use, you will need to obtain permission directly from the copyright holder. To view a copy of this licence, visit http://creativecommons.org/licenses/by/4.0/. The Creative Commons Public Domain Dedication waiver (http://creativecommons.org/publicdomain/zero/1.0/) applies to the data made available in this article, unless otherwise stated in a credit line to the data. 
and narrow streets prevent stagnant air from moving. This has caused a high rate of premature death, as well as a negative impact on mental abilities and perception [5].

In addition, a built environment's quality has a considerable effect on the psychological and organic health of users as well as the energy consumption of the building. Therefore, it is essential to achieve an acceptable level of indoor air quality and pollution, primarily $\mathrm{CO}_{2}$; thermal, visual, and acoustic comfort, and comfortable internal conditions for users while considering external environmental factors such as ventilation, natural lighting, and energy $[6,7]$.

Biomimicry is an excellent model for engineers and architects to follow when designing a building. Through natural processes and simulators, biological designs discover effective solutions to design problems. They are multifunctional, renewable, flexible, and adaptable. Therefore, this study proposes a method for enhancing the quality of the built environment, particularly in densely populated cities, by investing in building skin elements that apply biomimicry architecture mechanisms [8-10].

\section{Research aim and methodology}

The study's objective is to develop solutions from nature to contribute to the enhancement of the built environment's quality in densely populated cities. For this purpose, the study aims to determine the feasibility of applying alga-based building facade technology in Egypt's densely populated cities. The study explores the following research questions.

- What benefit does integrating PBR facades into commercial buildings provide?

- What are the implications of integrating algae technology on environmental and climate change issues?

- Is Egypt's climate appropriate and qualified to adopt and benefit from the algae facades?

\section{Methodology}

The methodology is divided into two sections: testing of the hypothesis and addressing the research questions:

-The theoretical study (qualitative research and data analysis) consists of three components:

- Study on the identification of algae and their incorporation into the building as a biomimicry architecture strategy.

- Study on the benefits associated with the incorporation of this technology into architecture.

- Analyzing the global response to algae technology by showcasing suggested buildings in different cities in the world, as there is only one actually built in Germany, as well as other examples of competitions, studies, and ongoing projects.

-Qualitative and quantitative approach to a pilot study and case study: 
- Energy consumption was determined for the building in Egypt considered for the case study and its counterpart in Germany, and the corresponding energy saving rates were calculated using mathematical equations.

- In addition, interviews were conducted to collect data on microalgae cultivation, and the data from the literature have analyzed the system as well as to ascertain the degree of acceptance of and satisfaction with this technology.

By using a holistic and inductive method, an analytical form is formulated to demonstrate how the algae-based building facade conserves the environment, natural resources, human health, and energy, while also adapting to climate change.

\section{Research limitations}

The application of algae facades as a form of bio-design systems was investigated by using an example of a commercial building in a densely populated city (Cairo Mall in Giza, Egypt); further, personal interviews with targeted groups of people were conducted. However, this study has only one precedent for building applications, which is Germany's Bio Intelligent Quotient (BIQ) apartment building [11].

Biomimicry in architectural design and planning produces living designs, obtaining the energy and water required for the facility from its location. It presents buildings made from local materials that are integrated and compatible with their environment and climate. In addition, it does not pollute the environment. Biomimicry-based architecture works in three levels, as shown in Fig. $1[12,13]$. This study focuses on the ecosystem level.

The interdisciplinary approach to using microorganisms or their products can be termed microbial biotechnology. Bioinspired climate-adaptive building skins behaving like living organisms can create an ecosystem that can provide a mutual relationship with the environment [14]. The parameters, criteria, and design problems with biomimetic building skin designs are the responsiveness of the building's skin to natural phenomena, such as sunlight, wind, and rain, and its ability to perform vital functions, such as breathing, carbon absorption, and water consumption. These can be understood and applied through the biodesign of the building skin [15].

The building's skin is vital in maintaining energy consumption and reducing $\mathrm{CO}_{2}$ percentage. Therefore, it is enhanced by using bio facades, specifically algae facades, which add other features to the building's skin, such as controlling natural lighting and thermal insulation and reducing thermal loads on the building. Algae are primary organisms living in a natural aquatic environment or an environment designed for them

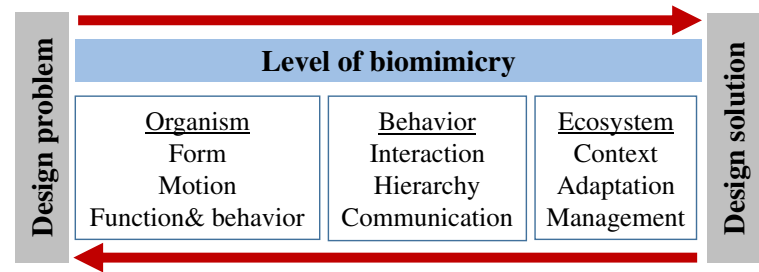

Fig. 1 Application of biomimicry in architectural design 
in a PBR, shown in Fig. 3. Photosynthesis in algae is more effective than in other plants, and therefore, they have a higher $\mathrm{O}_{2}$ production and $\mathrm{CO}_{2}$ absorption capacity $[16,17]$.

Owing to the PBR system's limitations about application and usage, it is not widely applied. The only building that uses a PBR facade system, called Solar Leaf, is the BIQ apartment building (2013) in Hamburg, Germany (Fig. 2), which converts solar energy at $10 \%$ efficiency. The system is inefficient in comparison to a typical photovoltaic system, which converts solar energy at a rate of $15-20 \%$. In addition, this system has limitations such as stringent control requirements for the microalgae environment, the requirement for a high glass facade, and the legal problem of microalgae cultivation on a building facade [18].

Although BIQ is the first and only actual real building in the world, there are many other projects as study and competition prizewinners (see Table 1; Figs. 3, 4, 5, and 6). Indeed, this is not an exhaustive list of such projects.

Producing bioenergy from microalgae not only generates clean energy but also contributes to greenhouse gas mitigation and has the potential to be a carbon-neutral power source of energy. Environmentally friendly building designs also provide financial benefits in the form of reduced taxes, operating costs, and energy costs, which lead to lower life cycle costs (LCCs) and an increase in rent costs without a decrease in occupancy [25].

\section{Methods and experiment}

This study aims to demonstrate that incorporating algae-based facade technology into the skin of buildings in densely populated cities as a biomimicry strategy contributes to enhancing the built environment's quality. For this result, the factors affecting the built environment can be categorized into two categories based on their type and measurement method, as shown in Fig. 7.

1- The first category contains information about the energy consumption of buildings and the $\mathrm{CO}_{2}$ concentration in the air, which can be determined through calculations and data inference.

2- The second category includes measurements of thermal, visual, and acoustic comfort and internal conditions; these relate to the sensory criteria, opinions, and the degree of acceptance of this technology by the professionalsand users and are measured through personal interviews [26].
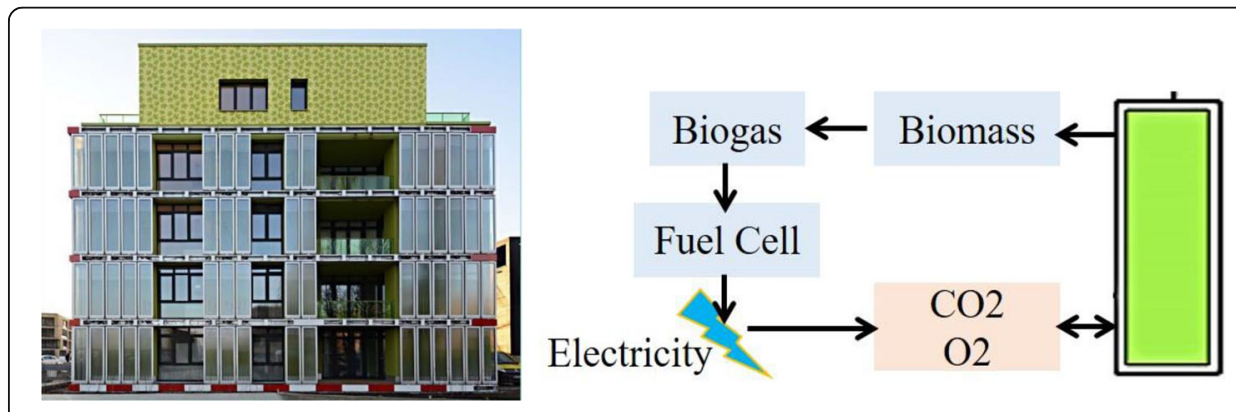

Fig. 2 Right: BIQ apartment [19, 20]. Left: Photobioreactor system 
Table 1 World examples of PBR facade projects

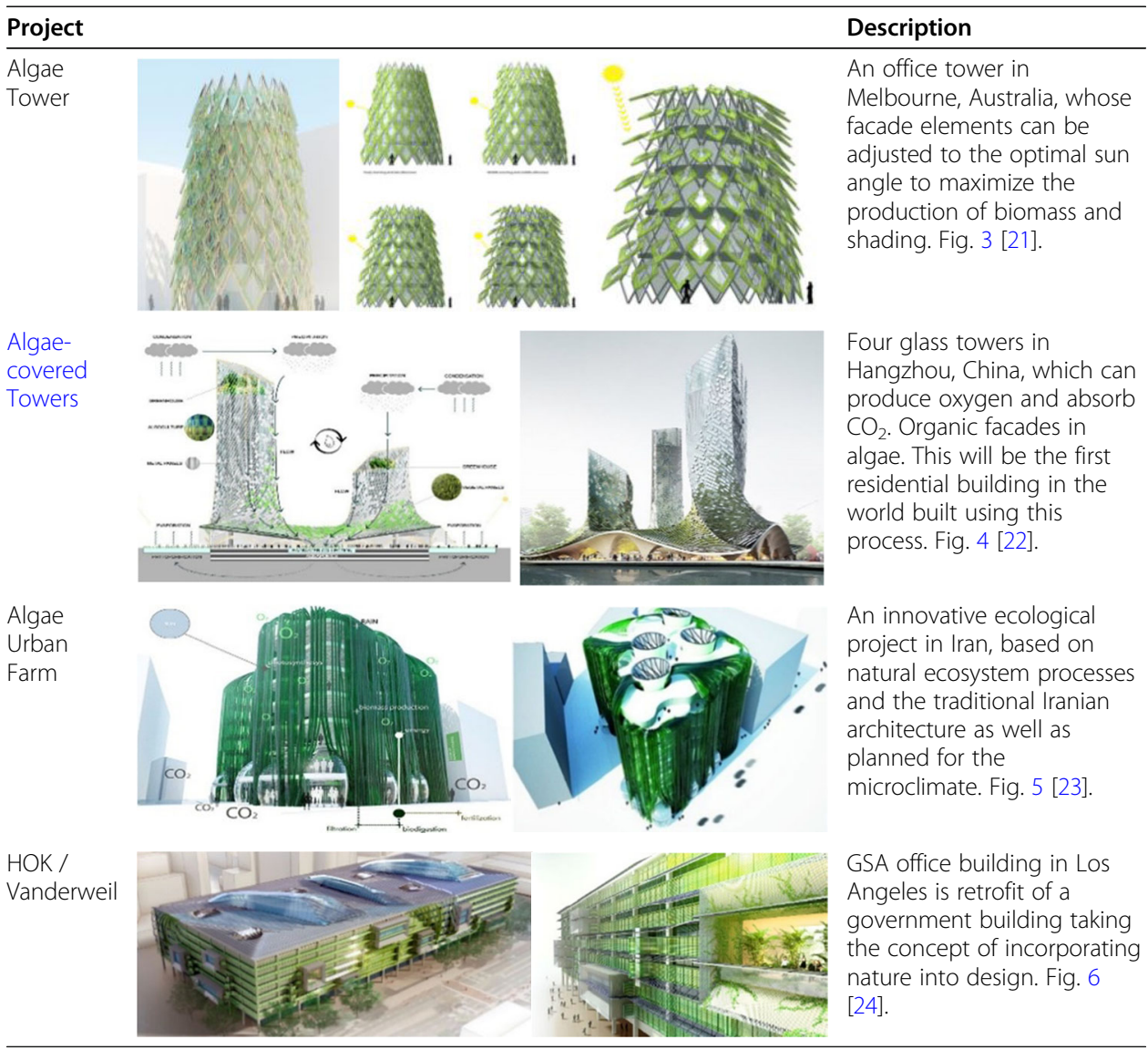

The case study building, Cairo Mall, is a multi-story commercial building, which is an example of a building type with high-energy consumption. It is located in the hot, arid climate zone of Giza Governorate, Egypt. We chose this building because it is located in a populated city with high traffic and population density, rare green areas, and high density of buildings. This is a landmark building in the region, built around 1985; it has a conditioned floor area of $5500 \mathrm{~m}^{2}$ and a volume of approximately $140000 \mathrm{~m}^{3}$. The building has a curtain wall clad with low-performance windows (Fig. 8). Commercial buildings require high-energy rates to operate. Because this building has a curtain

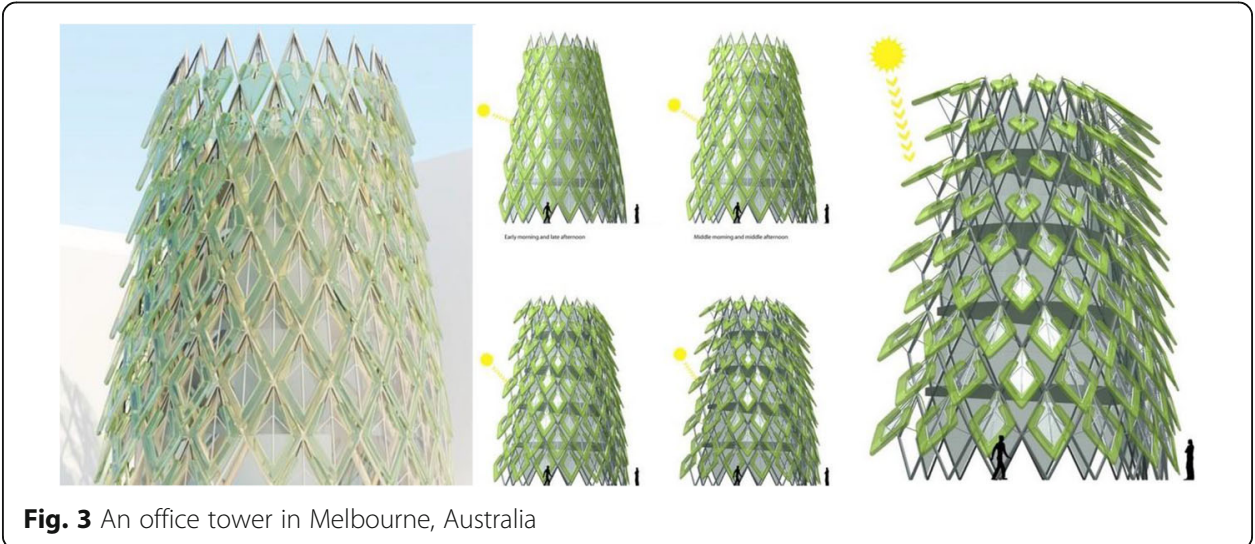




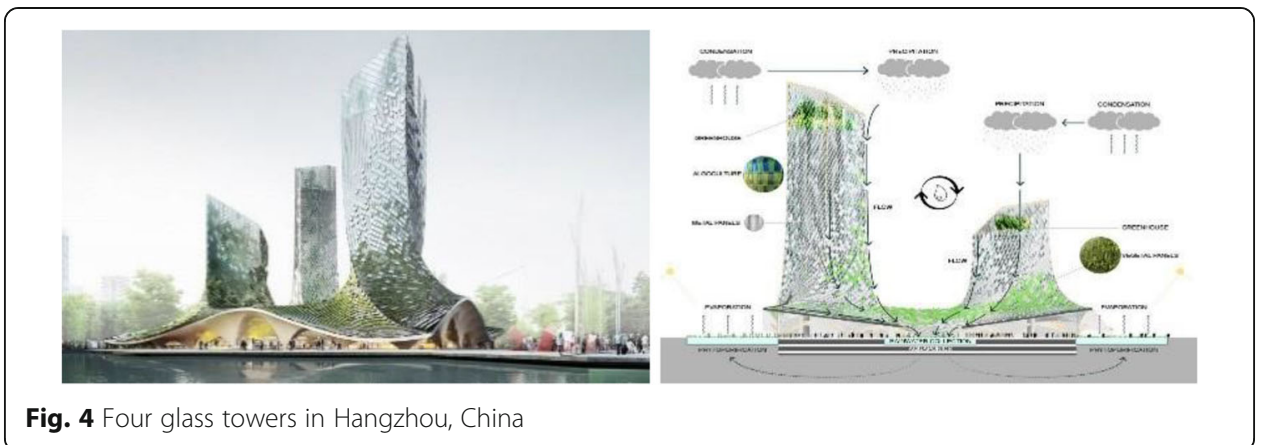

wall envelope, it has large energy consumption due to heating, ventilation, and air conditioning to improve the quality of the environment in its spaces.

The case study building is covered with glass facades as an innovative esthetic principle, despite the negative impact on the environment and contributes to the loss/ gain of heat. This study discusses the effectiveness of the solution for facades in which the curtain wall panels are replaced by algae-based facade panels [27, 28].

- The suggested algae facade system is a bioreactor integrated between two acrylic sheets. A nutrient liquid provides the environment for algae growth. It is $150 \mathrm{~cm}$ wide and $300 \mathrm{~cm}$ high, installed northeast, northwest at the Main Street facades, and supported by aluminum frames on four sides.

- The algae growth zone is an aquatic environment containing algae in addition to a set of pipes, mechanical systems, air pumps, and other water and filtration systems [29]..

- The algae growth apparatus comprises intake systems for supplying $\mathrm{CO}_{2}$ and growing algae (i.e., algae, nutrients, and medium) and discharging systems for emitting $\mathrm{O}_{2}$ and collecting grown algae [30-32] (Fig. 9).

- BIQ is the only actual building that uses the PBR facade system. Hence, in the pilot study, this building is analyzed as the primary precedent, and on the basis of this, the amount of electricity saved in the case study building is estimated.

- Note that the climate of Giza differs from that of Hamburg. The number of hours and the degree of sunshine is greater, which reflect in the heat generation rates by

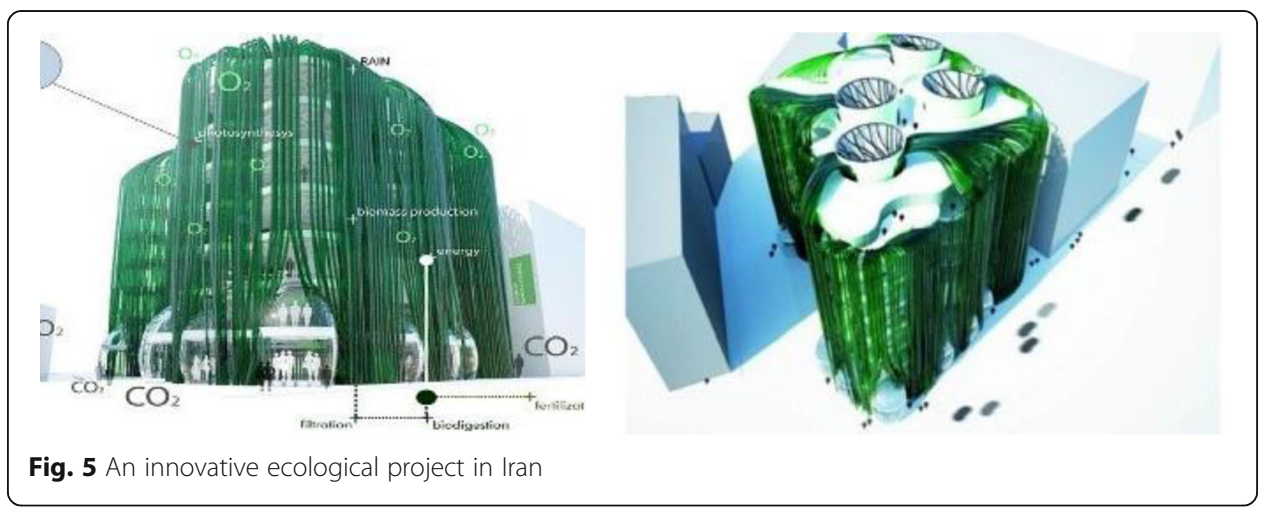




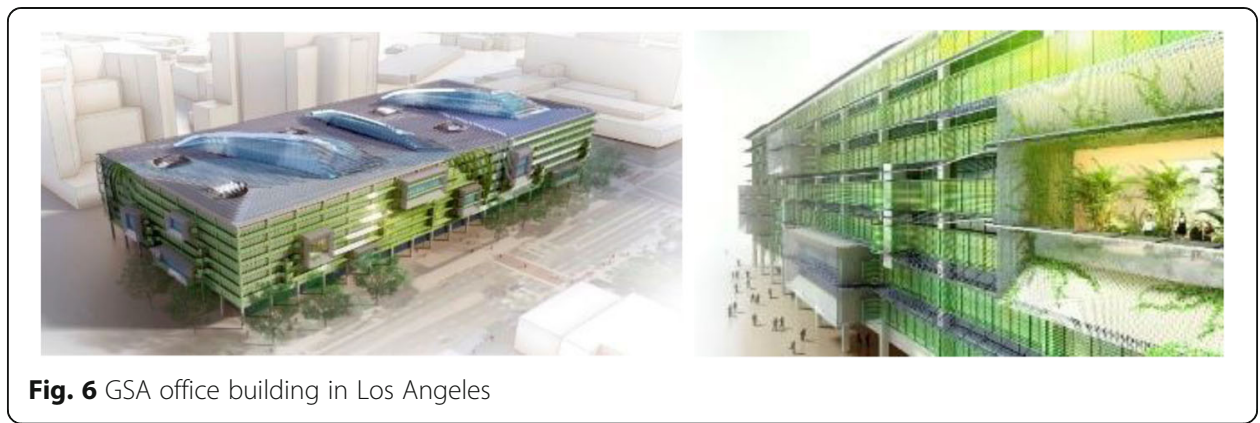

algae. In Germany, it is rainy throughout the year, and clouds obscure the sky about two-thirds of the day hours. Previous studies have confirmed that the increase in solar radiation and the number of daylight hours is directly proportional to the growth of algae and thus the performance of the building with algae-based facades (Table 2) [3339].

- This technology, its benefits, and the results of the study are discussed with a sample of respondents, and professionals and several stakeholders were interviewed regarding the feasibility of modifying the facades of the buildings in Giza, Egypt, with algae facades for improving the quality of the built environment.

\section{Calculations of energy production and carbon dioxide reduction}

The BIQ apartment building has a 200- $\mathrm{m}^{2}$ area of PBRs with each unit $70 \mathrm{~cm}$ wide, $270 \mathrm{~cm}$ high, and $8 \mathrm{~cm}$ thick; 129 modules were installed in the southeast direction and filled with microalgae through photosynthesis. The produced biomass removes $\mathrm{CO}_{2}$ and generates energy. The required information about the algae facade production is shown in Table 3 [40-43].

- From the case study building, the electricity consumption is approximately 182,500 $\mathrm{kW} / \mathrm{h}$ (a summer month bill, for example), which is considered a high rate of consumption [44].

- To measure the energy efficiency of the microalgae facade, the only variable between the original building and the retrofitted building is the building energy in the window system. The remaining variables such as the specification of the opaque wall, window-to-wall ratio, air infiltration rate, and building operational schedules remain the same between the two scenarios.

- A total area of $4500 \mathrm{~m}^{2}$ of the northeast and northwest façade and $3800 \mathrm{~m}^{2}$ of PBRs with each unit $140 \mathrm{~cm}$ wide, $280 \mathrm{~cm}$ high, and $8 \mathrm{~cm}$ thick suggest installing and filling with microalgae through photosynthesis.

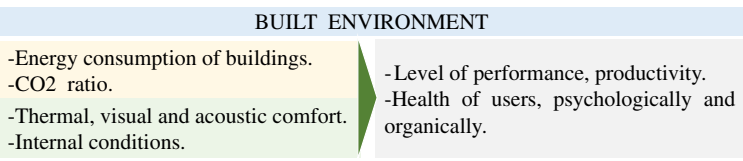

Fig. 7 Built environment parameters 

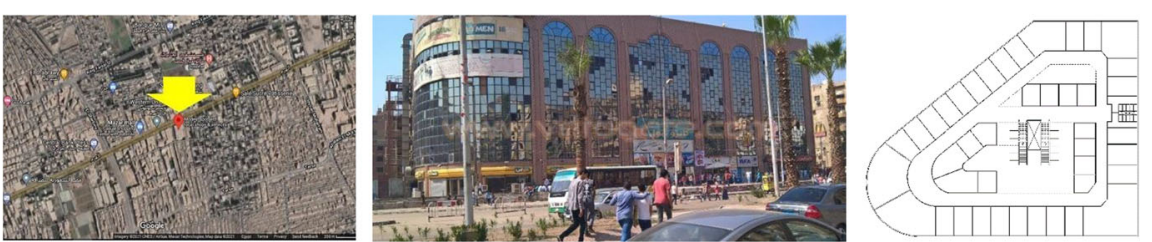

Fig. 8 Case study building Cairo Mall: from left to right, location (Google map), main elevation, typical plan sketch

-By arithmetic and mathematic relations, $=(Y \alpha / X) R$, where $\mathrm{X}$ is the PBR area in the BIQ building, $\mathrm{Y}$ is the PBR area in the case study building, ais electricity converted from the PBR in the BIQ building (unit: kilowatt/hour), is the expected electricity converted from the PBR in the case study building (unit: kilowatt/hour), and $R$ is the constant coefficient between the climate of Hamburg and Giza). In the same way, the expected reduction of carbon dioxide emissions per year is calculated.

\section{Interview}

Interviews were conducted with practitioners, residents, and stakeholders to ascertain their perceptions and concerns about this technology of cultivating algae building skin. This interview posed the question, "What is your opinion about the feasibility of retrofitting the facades of buildings in Giza with algae facades?" Table 4 shows the sample of respondents and their composition. The interviews were conducted after showing the participants a brief video and some photos about this technology.

\section{Results}

The study sheds light on the PBR technology of using algae in buildings, especially commercial buildings; it has multiple devices and systems to control the environmental conditions of the building, which constitute in energy consumption (electricity).

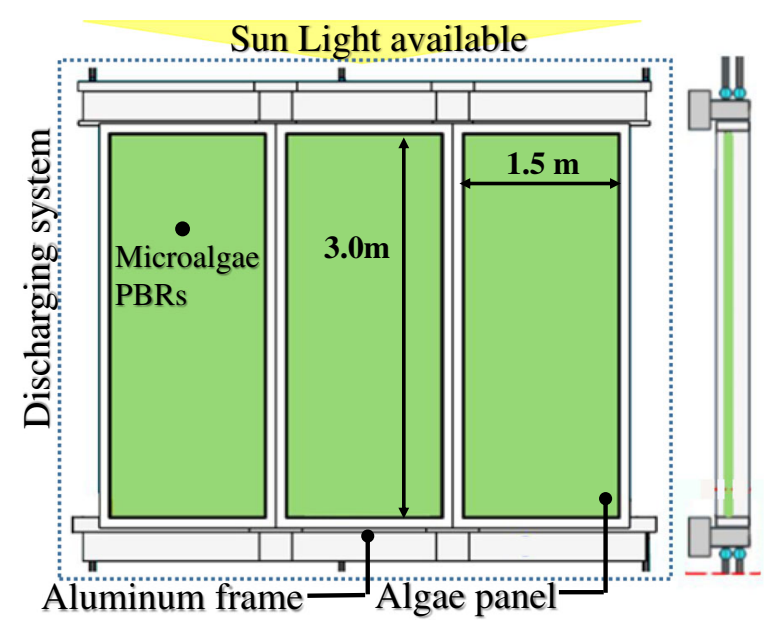

Fig. 9 PBR panel dimensions and details 
Table 2 Comparative climate data between Giza and Hamburg

\begin{tabular}{|c|c|c|c|c|c|}
\hline & \multicolumn{2}{|l|}{ Temperature } & \multirow{2}{*}{$\begin{array}{l}\text { Average } \\
\text { rainfall } \\
(\mathrm{mm})\end{array}$} & \multicolumn{2}{|l|}{ Sunshine } \\
\hline & $\begin{array}{l}\text { Average max. } \\
{ }^{\circ} \mathrm{C}\end{array}$ & $\begin{array}{l}\text { Average } \min . \\
{ }^{\circ} \mathrm{C}\end{array}$ & & $\begin{array}{l}\text { Average of sunshine hours } \\
\text { per day }\end{array}$ & $\begin{array}{l}\text { Average annual } \\
\text { sunshine }\end{array}$ \\
\hline Giza & 27.7 & 15.8 & 24.7 & 9:12 hour & 4000 h/year \\
\hline Hamburg & 12.3 & 4.6 & 457.3 & 6:8 hour & 1500 h/year \\
\hline
\end{tabular}

The study results indicate that, microalgae are a source of biofuel, which can be converted into electrical energy with special generators for application in building operation.

In addition, owing to the climate of the Egypt governorates, the application of this technology has high environmental advantages.

A. Mathematical calculation and analysis results

-Giza has more solar radiation than Hamburg. From the calculations for the case of Hamburg, being considered the minimum values, the converted electrical energy by the algae facades is approximately $85500 \mathrm{~kW} / \mathrm{h}$, which implies $45-50 \%$ of the electricity consumption in the building could be saved

-The algae facades are expected to reduce 100 tons of carbon dioxide emissions per year which is reflected in the internal environment of the building (Fig. 10).

B. Interview results

-Interviews analyzed four main categories: environmental, economic, technological, and social benefits. The results of the interview in the form of statistical data are shown in Fig. 11.

\section{Discussion}

Despite the efficiency of integrating PBR into facades, it only supplies about half of the electricity requirement in the case study building. As a result, additional clean energy technologies, such as photovoltaics, can be combined to maximize efficiency.

-The energy generated, $\mathrm{CO}_{2}$ absorbed, and the cost are all directly proportional to the area of the algae facade, as shown in Fig. 12.

-This technology is costly, which includes the cost of construction, operation, and the high amount of energy required to mix nutrients and maintain algae in suspension [45, 46]. The PBR cost in BIQ is approximately $€ 5$ million [47]. However, the technology is cost-effective in the long run due to its benefits.

Table 3 Photobioreactor panel energy indicators

\begin{tabular}{ll}
\hline Photobioreactor panel energy indicators & Value \\
\hline Biomethane production & $612 \mathrm{~m}^{3}$ methane/year \\
Net energy as methane & Approx. 4,541 kWh/year. \\
Net energy from heat & Approx. $6,000 \mathrm{kWh} /$ year \\
Carbon dioxide emission reduction & 6 tons $/$ year \\
Basic data per $\mathrm{m}^{2}$ bioreactor area biomass production & $900 \mathrm{~kg} / \mathrm{year}$ \\
Energy production from biomass & $345 \mathrm{kj} / \mathrm{m} 2 /$ day \\
Biogas production from biomass & $10.20 \mathrm{~L}$ methane $/ \mathrm{m}^{2} /$ day \\
Net annual energy supply & Approx. $4500 \mathrm{~kW} / \mathrm{h}$ of electricity
\end{tabular}

Note: Indicators for a $200-\mathrm{m}^{2}$ bioreactor area with 300 days of production/year

These values are considered minimum because of the more hours of sunshine in Giza than in Hamburg 
Table 4. Sample of respondents and a number of stakeholders interviewed

\begin{tabular}{lc}
\hline Respondent classification & Number \\
\hline Building contractor & 1 \\
Visitors and public & 9 \\
Tenants & 5 \\
Engineering & 6 \\
Architecture & 5 \\
Surrounding building owners & 4 \\
Inhabitants of the area & 6 \\
Researchers & 2 \\
Project manager & 2 \\
Government district engineer & 1
\end{tabular}

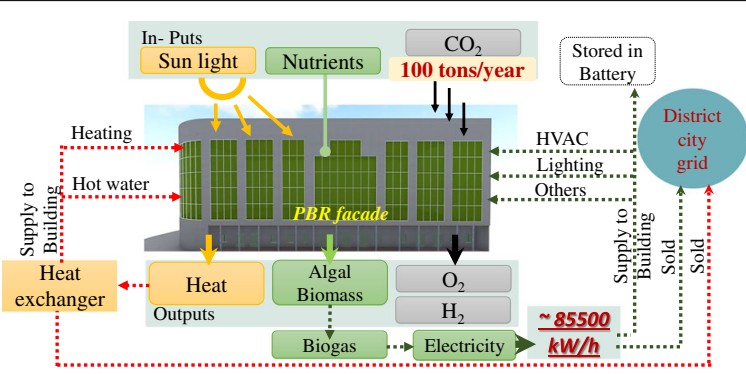

Fig. 10 Visualization of PBR integration in a building facade

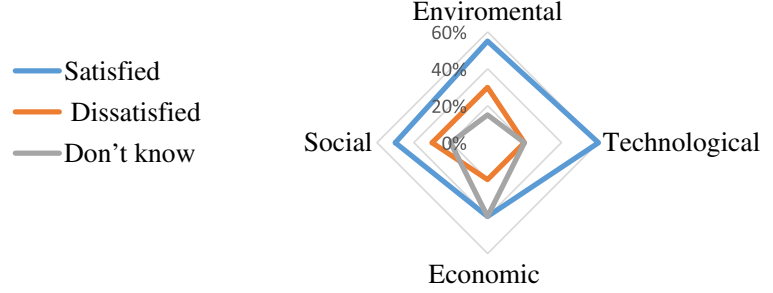

Fig. 11 Mean values of peoples' acceptance of the PBR facade technology

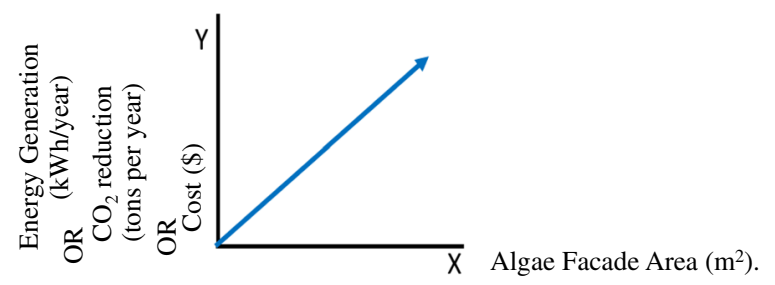

Fig. 12 Relation of the area of algae facade with energy generation, $\mathrm{CO}_{2}$ reduction, and cost 


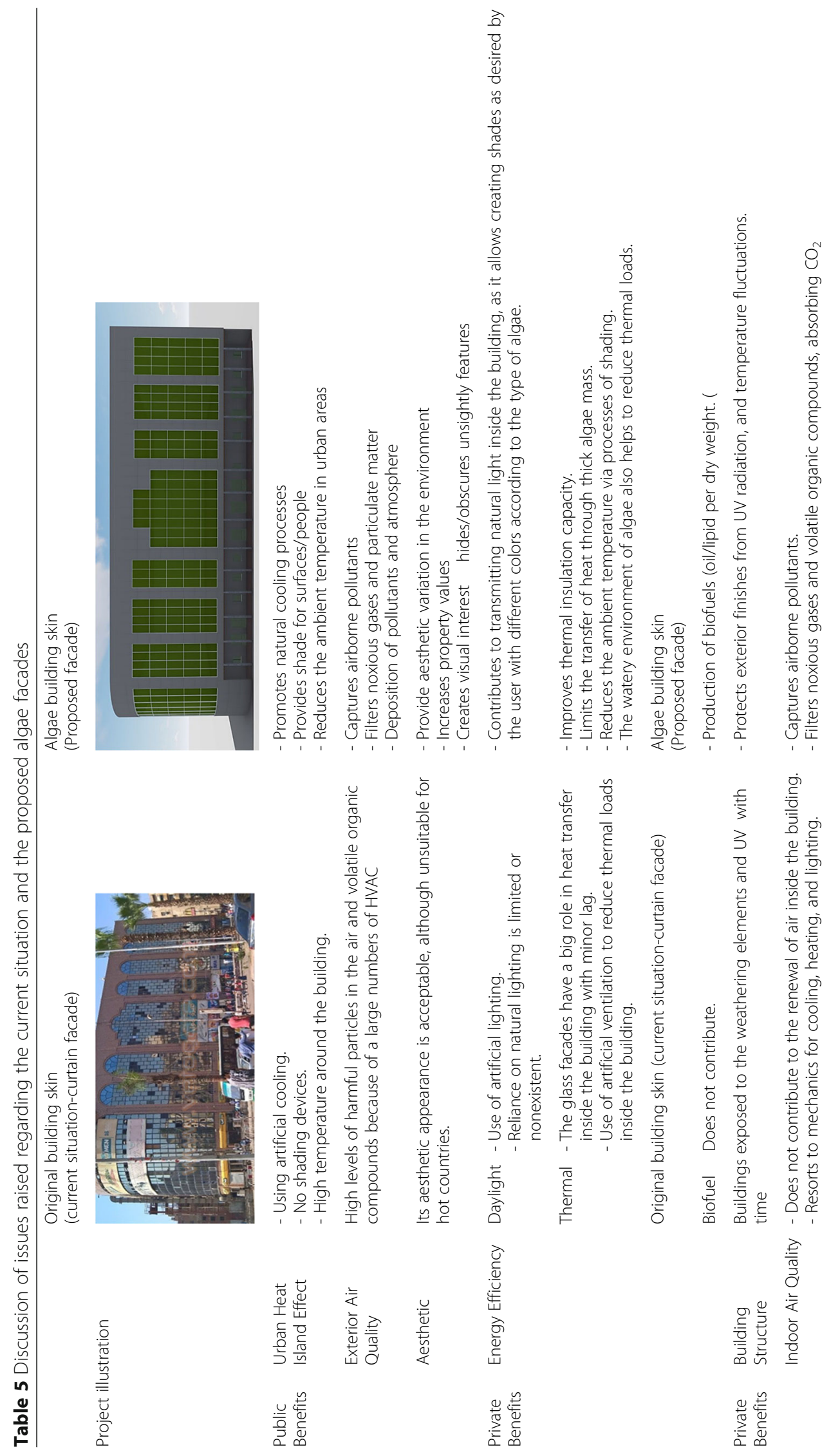




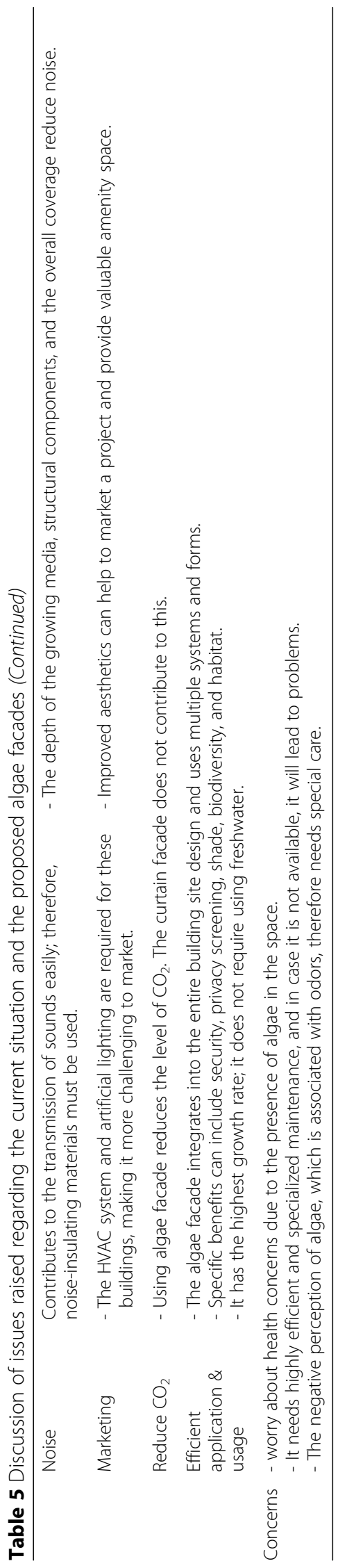


-When the responses of designers, architects, engineers, and the general public are compared, the majority of people's opinions on the quality of algae facades are consistent with those of the designers and architects. Approximately $20 \%$ of people had no idea about this new technology, but responded positively to using it. Although others had their concerns, more than $50 \%$ of those polled saw algae facades as efficient in terms of energy, esthetics, and pollution reduction. Table 5 summarizes the issues raised in the current and proposed situations, with discussion elements grouped together.

-It is obvious that the proposed technology can be used for other types of buildings in Egypt with high-energy consumption, such as office buildings and laboratories. In addition, it can be integrated into the urban environment.

-There is a need to integrate the efforts and diverse disciplines of concerned authorities and investors to develop an Egyptian model applicable to buildings to satisfy the growing demand for new, environmentally sustainable cities.

\section{Conclusion}

The findings in this study indicate that the use of algae technology in building facades as one of the strategies of biomimicry design contributes to increasing the efficiency of the built environment, which is reflected in user productivity. Algae facades also help to reduce the energy used in building operations as well as the energy used to control the environmental conditions inside the building. It can provide up to $50 \%$ or more of the building's energy consumption. Therefore, the research hypothesis is confirmed.

-Using the algae facade to generate renewable energy plays an important role in environmental preservation and contributes to the production of clean energy to address the non-renewable energy crisis. The production of oxygen and the absorption of carbon dioxide by the algae facades improve the internal and external environment of the building and help to reduce environmental pollution.

- The case study analysis and interviews with specialists, architects, and the general public indicated a strong preference toward adopting this new concept in design, with 50 to $60 \%$ of opinions supporting the aspect of reducing pollution, considering the diseases caused by environmental pollution in highly polluted cities, overcrowded places, and country capitals. Some were in favor of the idea because they desired modern and innovative technologies in the buildings, which would be reflected in the architectural aspects of the city in a way that kept up with technology. Some, particularly investors and owners, were concerned about the high cost. However, with the emphasis on the long-term benefits, these concerns could be alleviated. About $20-25 \%$ respondents
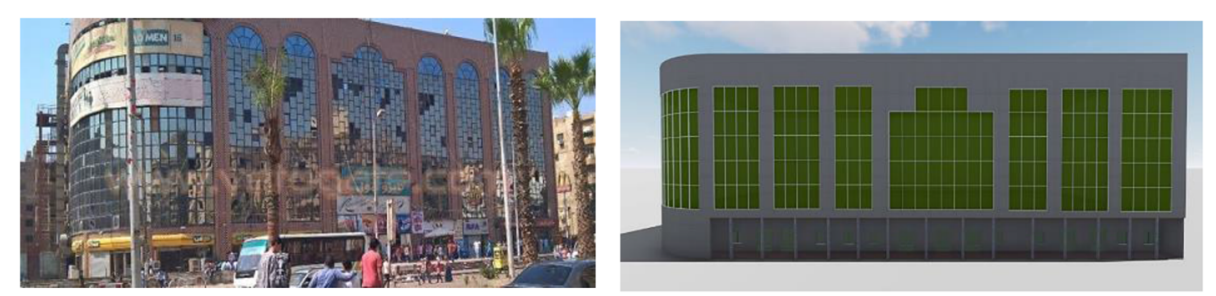

Fig. 13 Project illustration (current situation-curtain facade and Proposed facade) 
expressed concern about the maintenance and investment required to adopt this technology.

-Algae facades can be used on a variety of public buildings, including hospitals, office buildings, hotels, and others, particularly those that require a significant amount of energy to operate. Through the design of interactive facades, this gives a different and distinctive esthetic and deviates from the traditional forms of building facades.

-Through algae facades, it is possible to achieve the world, strategies, and trends toward zero-energy buildings, environmental preservation, and improved quality of life, despite the fact that biomimicry in general, and bio-algae interactive technology in particular, are still a relatively new field. With additional research, designers will gain a greater understanding of it, and the opportunity to apply what they have learned from nature to save the planet.

Abbreviations

PBR: Photobioreactors; BIQ: Bio Intelligent Quotient apartment building

\section{Acknowledgements}

Not applicable

Author's contributions

Not applicable

\section{Authors' information}

The author 'W.H' is associated with Architecture, Environmental Design at Ain Shams University (BSc. MSc., PhD.) and is a member in Advisory Committee - Egypt Society of Energy Efficiency Engineers and Investors.

\section{Funding}

Not applicable

\section{Availability of data and materials}

The datasets used and analyzed during the current study are available from the corresponding author upon request.

\section{Declarations}

\section{Competing interests}

The author declares that there are no competing interests.

Received: 10 April 2021 Accepted: 20 October 2021

Published online: 29 November 2021

\section{References}

1. NASA, "GHG emissions from 2000 to 2100," https://www.nasa.gov/, (Accessed June 10, 2019).

2. World Health Organization, "AirQ+: burden of disease due to air pollution manual" Last modified in December 2020, https://apps.who.int/iris/bitstream/handle/10665/337684/WHO-EURO-2020-1560-41311-56213-eng.pdf?sequence=1\&isA llowed=y. (Accessed June 20, 2021).

3. The Intergovernmental Panel on Climate Change (IPCC) is the United Nations body for assessing the science related to climate change," https://www.ipcc.ch/, (Accessed November 20, 2019).

4. IEA. CO2 Emissions from fuel combustion: Highlights, 2020 Edition. OECD/IEA; 2020. (Accessed August 16, 2021).

5. Dodman, D., (2009), "Blaming cities for climate change an analysis of urban greenhouse gas emissions inventories." Environment and Urbanization, International Institute for Environment and Development (IIED). Vol 21 (1): 185-201. pp. 185-201, https://journals.sagepub.com/doi/abs/10.1177/0956247809103016

6. Ashrae AS (2004) Standard 55-2004. "Thermal environmental conditions for human occupancy". American Society of Heating, Refrigerating and Air-Conditioning Engineers, Atlanta, GA, pp 20-26

7. Frontczak M, Wargocki P (2011) Literature survey on how different factors influence human comfort in indoor environments. Build Environ 46(4):922-937 https://doi.org/10.1016/j.buildenv.2010.10.021

8. The Biomimicry Institute: Biomimicry 3.8. (2013). "A biomimicry primer: biomimicry" 3.8. [ONLINE] Available at: http:// biomimicry.net/about/biomimicry/a-biomimicry-primer/. (Accessed may20, 2021).

9. El-Zeiny RMA (2012) Biomimicry as a problem solving methodology in interior architecture. Procedia Soc Behav Sci 50: 502-512. https://doi.org/10.1016/j.sbspro.2012.08.054

10. Helmy S. E. \& Aboulnaga M. M. (2020). Future Cities: The role of biomimicry in improving livability in megacities and mitigating climate change risks. In: Scott L., Dastbaz M., Gores C. (Eds.) Sustainable Ecological Engineering Design Springer, Cham. https://link.springer.com/chapter/10.1007/978-3-030-44381-8_3

11. International building exhibition IBA Humburg, "Smart material houses: BIQ". https://www.iba-hamburg.de/en/projects/ the-building-exhibition-within-the-building-exhibition/smart-material-houses/biq/projekt/biq.html (Accessed September 2, 2019). 
12. Tamayo U, Vargas G (2019) Biomimetic economy: human ecological-economic systems emulating natural ecological systems. Social Responsibility Journal 15(6):772-785. https://doi.org/10.1108/SRJ-09-2018-0241

13. Pawlyn M (2019) Biomimicry in architecture. Routledge, Riba Publishing, London, UK. https://doi.org/10.4324/978042934 6774

14. Gosztonyi S, Gruber P (2013) BioSkin-Forschungs - potenziale für bionischin-spirierte energieeffiziente Fassadentechnologien

15. Schleicher S (2015) Bio-inspired compliant mechanisms for architectural design: transferring bending and folding principles of plant leaves to flexible kinetics tractors

16. Wurm J, Pauli M (2016) SolarLeaf: The world's first bioreactive façade. Arq: Architectural Research Quarterly 20(1):73-79. https://doi.org/10.1017/S1359135516000245

17. Kim KH (2013) Beyond green: growing algae facade. ARCC Conference Repository

18. Up, B. (2015). The BIQ house: first algae-powered building in the world. Euro Portal Energy Efficiency Build 2015. http:// www.buildup.eu/en/practices/case/big-house-first-algae-powered-building-world (Accessed May 15, 2019).

19. IBA, Hamburg webpage: http://www.iba-hamburg.de/en/themes-projects/the-building-exhibition-within-the-buildingexhibition/smart-material-houses/biq/projekt/biq.html. (Accessed march 15, 2020).

20. Muthu SS (2016) Environmental footprints and eco-design of products and processes. SGS Hong Kong Limited, p 93

21. Algae tower, photo-bio-reactor façade, Australia. https://uooustudio.com/algae-tower, (Accessed Sept 1, 2021).

22. Algae-covered Towers in Hangzhou, "Clean up the air thanks to algae buildings". https://www.divercitymag.be/en/clea n-up-the-air-thanks-to-algae-buildings-2/ . (Accessed Sept 1, 2021).

23. Algae urban farm: eco-project Britain foe Iran, https://thelastnewspaper.com/algae-urban-farm-eco-project-from-britainfor-iran/. (Accessed Sept 1, 2021).

24. Murrye Berardm HOKNanderweil process zero concept building: as green as. Algae? Mon, Nov 28, 2011, http:// buildipedia.com/aec-pros/featured-architecture/hok-vanderweil-process-zero-concept-building-as-green-asalgae . (Accessed Sept 1, 2021).

25. Biloria N, Thakkar Y (2020) Integrating algae building technology in the built environment: a cost and benefit perspective. Frontiers of Architectural Research 9(2):370-384. https://doi.org/10.1016/j.foar.2019.12.004

26. Anderson JE, Wulfhorst G, Lang W (2015) Energy analysis of the built environment-a review and outlook. Renew Sust Energ Rev 44:149-158. https://doi.org/10.1016/j.rser.2014.12.027

27. Stec, W. J., Van Paassen, A. H. C., \& Maziarz, A. (2005). Modelling the double skin façade with plants. Energy and Buildings, Vol.37, (2005), 419-427.

28. Manz H, Frank T (2005) Thermal simulation of buildings with double-skin façades. Energy and Buildings 37(11):11141121. https://doi.org/10.1016/j.enbuild.2005.06.014

29. Mata TM, Martins AA, Caetano NS (2010) Microalgae for biodiesel production and other applications: a review. Renew Sust Energ Rev 2:217-232

30. Martokusumo, W., Koerniawan, M. D., Poerbo, H. W., Ardiani, N. A., \& Krisanti, S. H. (2017). Algae and building façade revisited. a study of façade system for infill design. J Archit Urban, 41(4), pp296-304, 296, DOl: https://doi.org/10.3846/2 0297955.2017 .1411847

31. Singh, R. N., \& Sharma, S. (2012). Development of suitable photobioreactor for algae production-a review. Renew Sust Energ Rev, 16(4), 2347-2353 (Accessed March 9, 2020), DOl: https://doi.org/10.1016/j.rser.2012.01.026.

32. Kim KH, Green B (2013) Growing algae facade. In: Proceedings of the ARCC Conference Repository, Charlotte, NC, USA, Issue 12, 15-2-2014

33. Fadli A (2016) The feasibility of photobioreactor in a building façade on a high solar radiation area. master thesis, University of Florida, pp 42-103

34. Singh SP, Singh P (2015) Effect of temperature and light on the growth of algae species: a review. Renew Sust Energ Rev 50:431-444. https://doi.org/10.1016/j.rser.2015.05.024

35. "BIQ House + Solar Leaf - the use of microalgae Hamburg, Germany" Access from https://pocacito.eu/sites/default/files/ BIQhouse_Hamburg.pdf (Accessed May 31, 2021).

36. Central Data Catalog, industry-electricity_energy, egy-capmas-solarenergy-2015, https://censusinfo.capmas.gov.eg/Meta data-ar-v4.2/index.php/catalog/522/study-description (Accessed Sept. 2, 2021).

37. Al Jazirah Magazine, Tenkzar Sfuk: Cloudy Germany benefits from solar energy, Tuesday 14/08/2007 G Issue 231, https:// www.al-jazirah.com/magazine/14082007/karg2.htm (Accessed Sept. 2, 2021).

38. The solar atlas of Egypt, pp.4-61, http://nrea.gov.eg/Content/files/solaratlasreport.pdf

39. Accuweather https://www.accuweather.com/ (Accessed Sept. 2, 2021).

40. Blair MF, Kokabian B, Gude VG (2014) Light and growth medium effect on Chlorella vulgaris biomass production. Journal of Environmental Chemical Engineering 2(1):665-674. https://doi.org/10.1016/j.jece.2013.11.005

41. EU Buildings - Smart Material House BIQ: http://www.buildup.eu/en/practices/cases/biq-house-first-algae-poweredbuilding-world, (Accessed march 15, 2020).

42. The European portal for energy efficiency in buildings. The BIQ House: first algae-powered building in the world | Build Up. EUR Portal Energy Efficiency Build 2015. http://www.buildup.eu/en/practices/cases/biq-house-first-algae-poweredbuilding-world (accessed May 27, 2021)

43. Das MP (2015) Bioelectricity production using algae in microbial fuel cell. Der Pharma Chemical, vol 7(11):8-10 http:// derpharmachemica.com/archive.html

44. Ministry of Electricity and Renewable Energy - Egyptian Electricity Holding Company - South Cairo Electricity Distribution Unit - General Administration for Monitoring Major Subscribers - Electricity bill 7/2019

45. Kunjapur AM, Eldridge RB (2010) Photobioreactor design for commercial biofuel production from microalgae. Ind Eng Chem Res 49(8):3516-3526. https://doi.org/10.1021/ie901459u

46. Sardá RC, Vicente CA (2016) Case studies on the architectural integration of photobioreactors in building facades. In: Nano and Biotech Based Materials for Energy Building Efficiency. Springer, Cham, pp 457-484

47. Roedel C, Petersen JP (2013) Smart Material House BIQ. IBA Hamburg GmbH

48. Aldawoud A (2017) Assessing the energy performance of modern glass facade systems. In: MATEC Web of Conferences (Vol. 120, p. 08001). EDP Sciences 
49. Martello NZ, Secchi S, Fausti P, Cellai G, Santoni A (2015) Analysis of direct and flanking sound transmission between rooms with curtain wall facades. Energy Procedia 78:164-169. https://doi.org/10.1016/j.egypro.2015.11.133

50. Speed of sound, university physics, volume 1, https://courses.lumenlearning.com/suny-osuniversityphysics/chapter/17-2speed-of-sound/ . (accessed October 6, 2021)

\section{Publisher's Note}

Springer Nature remains neutral with regard to jurisdictional claims in published maps and institutional affiliations.

Submit your manuscript to a SpringerOpen ${ }^{\odot}$ journal and benefit from:

- Convenient online submission

- Rigorous peer review

- Open access: articles freely available online

- High visibility within the field

- Retaining the copyright to your article

Submit your next manuscript at $\boldsymbol{\nabla}$ springeropen.com 